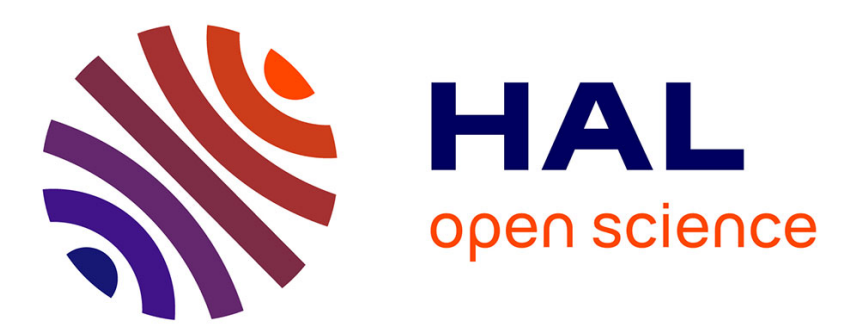

\title{
Aiming for the management of the small hive beetle, Aethina tumida, using relative humidity and diatomaceous earth
}

\author{
Bronwen Cribb, Steven Rice, Diana Leemon
}

\section{To cite this version:}

Bronwen Cribb, Steven Rice, Diana Leemon. Aiming for the management of the small hive beetle, Aethina tumida, using relative humidity and diatomaceous earth. Apidologie, 2013, 44 (3), pp.241-253. 10.1007/s13592-012-0173-6 . hal-01201289

\section{HAL Id: hal-01201289 \\ https://hal.science/hal-01201289}

Submitted on 17 Sep 2015

HAL is a multi-disciplinary open access archive for the deposit and dissemination of scientific research documents, whether they are published or not. The documents may come from teaching and research institutions in France or abroad, or from public or private research centers.
L'archive ouverte pluridisciplinaire HAL, est destinée au dépôt et à la diffusion de documents scientifiques de niveau recherche, publiés ou non, émanant des établissements d'enseignement et de recherche français ou étrangers, des laboratoires publics ou privés. 


\title{
Aiming for the management of the small hive beetle, Aethina tumida, using relative humidity and diatomaceous earth
}

\author{
Bronwen W. CRIBB ${ }^{1}$, Steven J. Rice ${ }^{2}$, Diana M. LEEMON ${ }^{2}$ \\ ${ }^{1}$ Centre for Microscopy \& Microanalysis and School of Integrated Biology, The University of Queensland, \\ Brisbane, Queensland 4072, Australia \\ ${ }^{2}$ Agri-Science Queensland, DAFF Ecosciences Precinct, GPO Box 267, Brisbane, Queensland 4001, Australia
}

Received 5 September 2011 - Revised 3 October 2012 - Accepted 10 October 2012

\begin{abstract}
Small hive beetles (SHBs) are a global pest of European honeybee colonies. In the laboratory, the survival of adult SHBs was evaluated in relation to relative humidity $(\mathrm{RH}=56,64,73,82$ and $96 \%)$ and treatment with diatomaceous earth (DE) across 4 days. Low RH reduced survival. The application of DE reduced survival in addition to RH. Adults treated with corn flour (control) showed no difference in survival from untreated beetles. Scanning electron microscopy images showed no scarification of adult beetle cuticle after exposure to DE; therefore, water loss is likely facilitated through non-abrasive means such as the adsorption of cuticular lipids. The data agree with the hypothesis that DE causes mortality through water loss from treated insects. Egress, ingress, mortality and the egg-laying behaviours of beetles were observed in relation to a popular in-hive trench trap with and without the addition of DE. Traps filled with DE resulted in $100 \%$ mortality of beetles compared with $8.6 \%$ mortality when no DE was present. A simple method for visually determining beetle sex was used and documented.
\end{abstract}

\section{Absorbicide ${ }^{\circledR}$ / Apis mellifera / European honeybee / insect pest / beetle trap}

\section{INTRODUCTION}

Diatomaceous earth (DE) is a powder composed of unicellular/colonial silicified skeletons of diatoms (algae). For insect pest management, it is used principally in the control of grain beetles (Golob 1997; Korunic 1998; Mewis and Ulrichs 2001; Stadler et al. 2012, among others). However, its application has been shown to be of use in the control of cockroaches and silverfish (Faulde et al. 2006); Mole crickets (Thompson and Brandenburg 2006); the potato ladybird, Epilachna vigintioctopunctata; and a lepidopteran pest caterpillar, Spodoptera litura

Corresponding author: B.W. Cribb,

b.cribb@uq.edu.au

Manuscript editor: Yves Le Conte
(Mucha-Pelzer et al. 2008). DE has also been used in the control of internal parasitic infections in poultry (Bennett et al. 2011). The way in which DE acts to kill arthropods is widely accepted to be via the removal or adsorption of the epicuticular lipid layers causing excessive water loss through the cuticle (Ebeling 1961; Mewis and Ulrichs 2001; Ulrichs et al. 2006). Applied DE products (i.e. from different sources) have different efficacies: they show differences in the mortality and efficacy related to the surface area of the product, humidity and temperature factors; also, efficacy differs amongst target insects (Ebeling 1961; Fields and Korunic 2000).

The small hive beetle (SHB), Aethina tumida Murray (Coleoptera: Nitidulidae), is a global pest and continues to cause large-scale economic losses within the apiary industry (Lounsberry et 
al. 2010; Neumann et al. 2010; Annand 2011). The use of DE is of interest to keepers of the European honeybee, Apis mellifera L., because controls that produce results with the fewest environmental impacts are the most appealing.

Relative humidity ( $\mathrm{RH}$ ) appears to impact the survival of stored product beetles in relation to treatment with DE (Völk et al. 2004). It is not known how RH affects the survival of SHB when $\mathrm{DE}$ is applied or whether factors such as the presence or absence of food modify the effect. But Buchholz et al. (2009) have shown that DE does enhance mortality and may be useful in the control of pupation and adult emergence and, possibly, as an in-hive treatment. The current study takes the topic further by addressing the survival of adult SHBs in relation to $\mathrm{RH}$ and in combination with a DE treatment through laboratory studies.

\section{MATERIALS AND METHODS}

\subsection{Cultures and materials used in experimentation}

\subsubsection{Beetle cultures}

The adult SHBs used for this study were obtained from a laboratory colony originally established late in 2007 using adult and larval SHBs sourced from Queensland beehives. Additional adult and larval SHBs obtained from various infested beehives in Queensland and New South Wales were added to the colony during the following 3 years to maintain colony vigour. The colony was established in the insectary at The Animal Research Institute Yeerongpilly, Queensland, and then transferred to the Ecoscience Precinct, Dutton Park, Queensland.

Adult beetles were kept under a 12:12-h light/dark regime, whilst the larvae and pupae were kept in continuous darkness. The temperature of the insectaries was kept at $27{ }^{\circ} \mathrm{C}$ and $\mathrm{RH}$ at $65 \%$.

Larvae were reared in black plastic bags $(19 \times$ $14.5 \mathrm{~cm})$ placed on top of a 12-cm-deep sand $(25 \%$ moisture $)$ in plastic boxes $(22 \times 21 \times 21 \mathrm{~cm})$. The bags were left open at the top. Numerous small holes (diameter, $1 \mathrm{~mm}$ ) were made in the lids of the boxes to provide ventilation. Each bag contained brood comb, pollen and honeycomb food stock obtained from beehives. The contents of the bag were regularly moistened with water. Thirty beetles (15 males and 15 females, determined via the difference in anal sclerite) were added to each black plastic bag so that eggs would be laid. The larvae produced matured after 12-15 days to the wandering stage and then crawled from the bag via the open top to burrow into the sand. At 17-20 days, the empty bag was removed and discarded. Subsequent pupation of the beetles occurred within the sand in the plastic box and lasted for 2 weeks. Once beetles started to emerge up through the sand and into the space above, one to two pieces of moistened, crumpled paper towel were placed on the sand to act as a harbourage and to prevent the beetles from dehydrating. At regular intervals, the adult beetles were removed and placed into separate plastic boxes $(22 \times 21 \times 21 \mathrm{~cm})$ with ventilated lids where they were maintained until required for experiments or for colony continuation.

Adult SHB were fed on a diet of granular white sugar (sucrose, $\mathrm{CSR}^{\circledR}$ sugar brand; Sugar Australia, Yarraville, Victoria) provided in a 9-cm Petri dish lid. A sponge (6× $4 \times 0.2 \mathrm{~cm}$; Wettex ${ }^{\circledR}$, Diversey Australia Pty. Ltd, Wetheril Park, NSW) dampened with water was provided in each box to provide moisture for the adult beetles. Pieces of damp crumpled paper towel were placed in the boxes to act as harbourages for the adult beetles. Female beetles were 1-2 weeks old when used in the experiments.

\subsubsection{Adult beetle sexing}

Squeezing the abdomen of a beetle is a useful way to see the genitalia, which are extruded with applied pressure. However, this often damages the beetles. Therefore, the sex of adult SHB was determined by examining the ventral abdominal sclerites (Figure 1). When viewing the beetles from the ventral surface, it could be seen that males had a thickened terminal sclerite which was absent in females (Figure 1a, c). The photographs in Figure 1b, d, e show the abdomen squeezed in order to confirm the link between the appearance of the sclerite and the sex of the beetle.

\subsubsection{Diatomaceous earth}

The DE used in this study to investigate the effect on survival of SHB was Absorbicide ${ }^{\circledR}$ (Mount Sylvia Diatomite Pty. Ltd, Australia). It was chosen because 


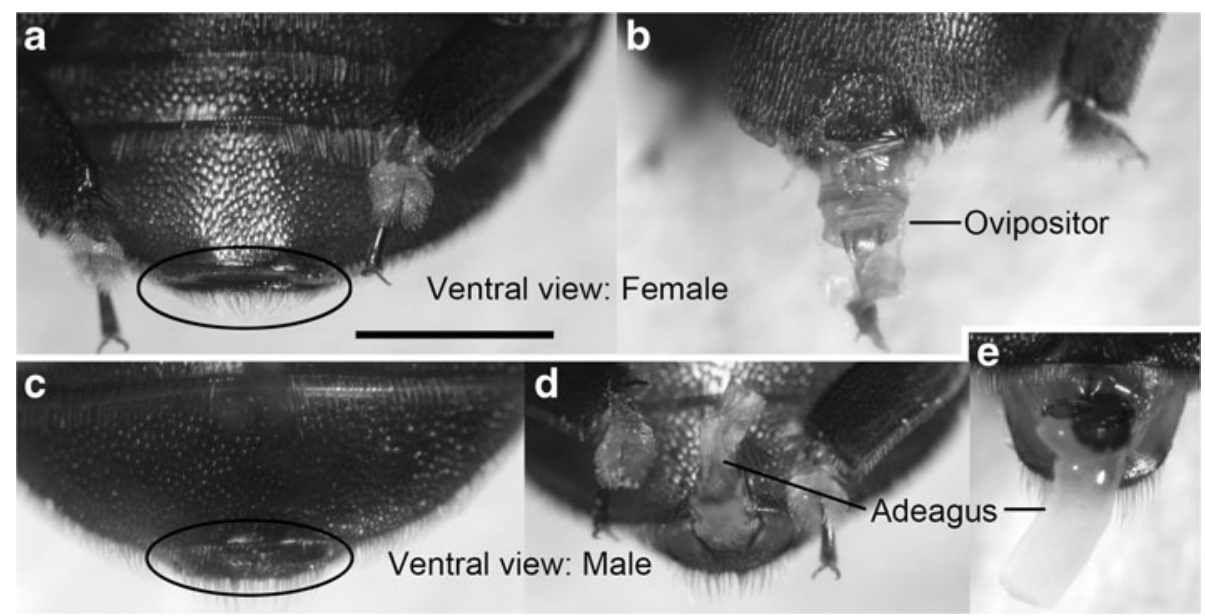

Figure 1. Ventral abdomen of small hive beetle, A. tumida. a Female. Bar, $1 \mathrm{~mm}$. b Female with ovipositor extended. c Male. d Male with adeagus extended and ventral sclerite seen surrounding the adeagus. e Male adeagus extended proximally. The black circle delineates the area used to determine the sex of the beetle.

this product is readily available to apiarists and registered by the Biological Farmers of Australia for use on organic farms.

\subsubsection{Yeast identification}

The yeast, Kodamaea ohmeri, has been found associated with SHB and is implicated in hive fermentation (Brenda et al. 2008). This yeast has been used as part of a baiting regime for monitoring the beetles (Torto et al. 2010). It was therefore used as an attractant bait in bioassay 1 (Section 2.2). To obtain the yeast, yeast colonies were isolated from beehive materials infested with SHB and sub-cultured for pure culture in the authors' laboratory. K. ohmeri was grown for 4 days at $30{ }^{\circ} \mathrm{C}$ on plates (diameter, $90 \mathrm{~mm}$ ) of $\mathrm{BBL}{ }^{\circledR}$ Sabouraud Dextrose Agar (Becton, Dickinson and Company, USA). Pure cultures were sent to the molecular mycology laboratory of A/Prof W. Meyer at Westmead hospital, Australia, for identification. The ITS region of the $5.8 \mathrm{~s}$ ribosomal gene was sequenced to confirm the species identity against similar sequences deposited in GenBank.

\subsection{Bioassay 1: behaviour and survival of beetles in relation to traps used in-hive}

Bioassay 1 tested the following two hypotheses: (1) the use of DE within trench traps (Figure 2a) results in greater mortality of SHB than the use of trench traps without DE and (2) the use of trench traps containing DE stops SHB egress and breeding outside the traps.

There were nine replicates for treatment and for control. Each replicate consisted of a chamber with one beetle trap (with or without DE), 40 beetles, sugar, crumpled paper, a moist sponge and an attractant bait. The chambers were incubated in the dark at $27{ }^{\circ} \mathrm{C}$. Mortality was assessed at 7 days. Details are provided below.

Each replicate chamber consisted of a large plastic container $(20 \times 40 \times 8 \mathrm{~cm})$ with a gauze insert in the lid to prevent escape of beetles and provide air circulation. The gauze had a thread size of $0.1 \mathrm{~mm}$ and a hole size of 0.15 - to $0.30-\mathrm{mm}$ diameter. The trap selected for use was a commonly used in-hive trench trap called AJ's Beetle Eater ${ }^{\circledR}$ trap (Quality Beekeeping Supplies, Sumner Park, Brisbane, Queensland, Australia). Traps in the treatment replicates were filled to a half depth with DE.

White granulated sugar was supplied as a source of food for the beetles. It was contained in a $2-\mathrm{cm}$ diameter bottle cap. The moistened sponge provided water. The attractant bait was designed to act as an oviposition site to enable assessment of whether reproduction would occur if the DE-coated beetles escaped from the traps. It was made from a $1-\mathrm{cm}$ cube of bee protein cake (C.B. Plamer \& Co., 

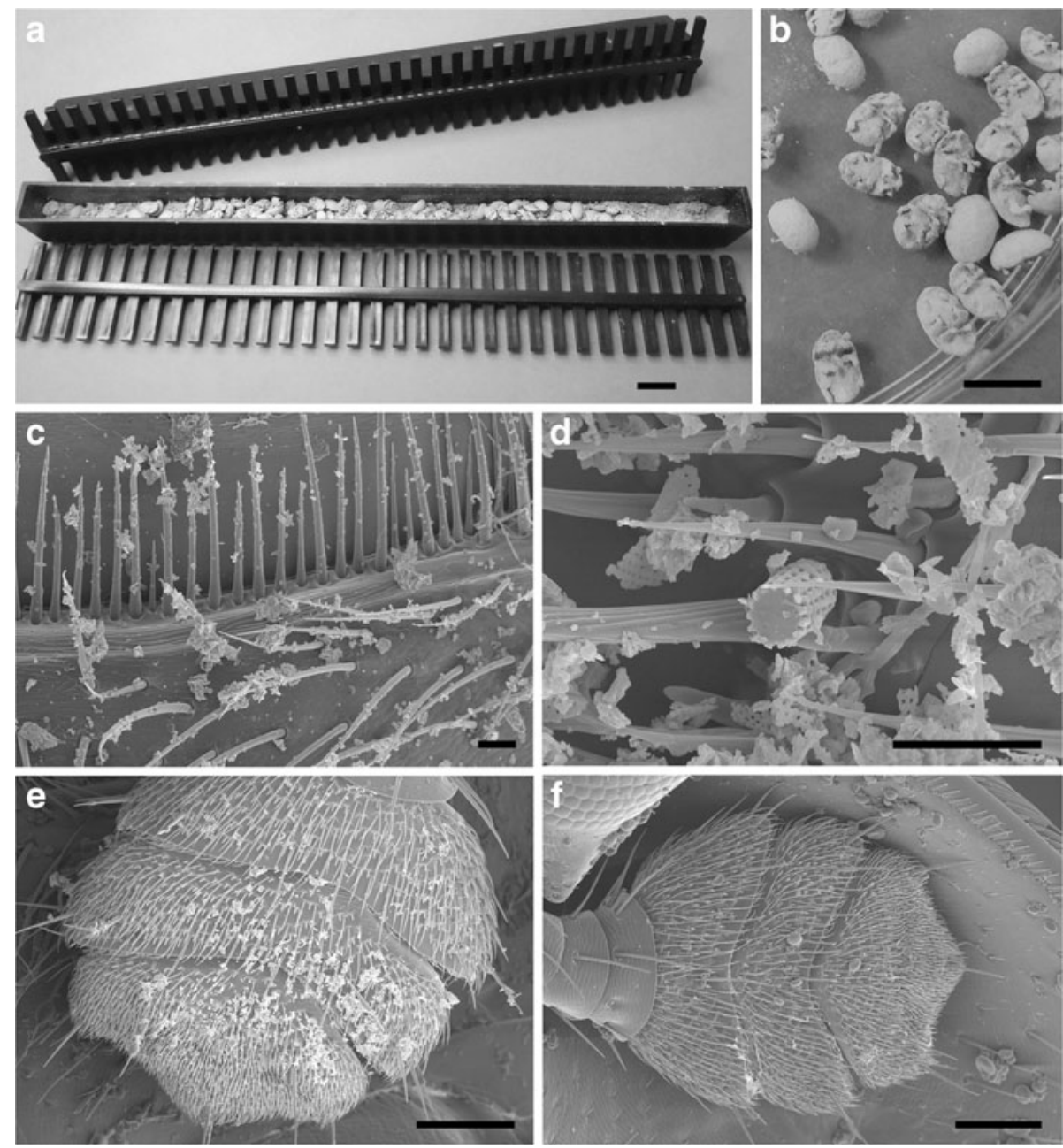

Figure 2. Images of small hive beetle, A. tumida. a A common in-hive trench trap with diatomaceous earth and beetles. Bar, $1 \mathrm{~cm}$. b Dead beetles coated with DE from the trap. Bar, $1 \mathrm{~cm}$. c-f Scanning electron micrographs. c Surface of beetle sternum with no indication of scarification. Bar, $20 \mu \mathrm{m}$. d DE on sensilla. Bar, $10 \mu \mathrm{m}$. e Antenna coated with DE. Bar, $100 \mu \mathrm{m}$. f Antenna coated with corn flour. Bar, $100 \mu \mathrm{m}$.

Queensland, Australia) adjacent to a glass Petri dish (diameter, $10 \mathrm{~cm}$ ) containing six pieces of filter paper moistened with $12 \mathrm{~mL}$ of liquid culture of the SHBassociated yeast (K. ohmeri).

\subsection{Examination of beetle cuticle with scanning electron microscopy}

The hypothesis tested was that DE scarifies the surface cuticle of adult beetles and is broadly distributed over the surface of the beetle.
Scanning electron microscopy (SEM) was used to assess any damage or scarification caused to the cuticle by exposure to DE and to examine the distribution of DE over the beetle. Ten beetles that died after dousing with DE were mounted on individual 12-mm aluminium stubs using adhesive carbon-impregnated tabs and sputter-coated to a thickness of $\sim 10-\mathrm{nm}$ platinum. The adults were observed using an electron beam of $8-10 \mathrm{kV}$ in a 6300FE or 6460LV SEM (JEOL, Tokyo, Japan). For comparison, SHBs not treated with DE and those 
dusted with corn flour were assessed using the same observational protocol.

\subsection{Bioassays 2, 3 and 4: effect of relative humidity and particulates on beetle survival}

Bioassay 2 tested the hypothesis that the application of DE to SHB significantly increases mortality, but is dependent on relative humidity.

There were three replicates. Each replicate consisted of five humidity chambers (equal to five humidity treatments) and, within each chamber, two DE treatments (with or without) with four plastic containers (equal to four experimental units). There were 10 beetles each ( $=10$ samples) per experimental unit. Chambers were kept at $27{ }^{\circ} \mathrm{C}$ in the dark. Survival was assessed daily for 4 days.

The humidity chambers were large sealed plastic boxes $(33 \times 22 \times 13 \mathrm{~cm})$ each holding a different saturated salt solution:

- Chamber 1: $55.6 \%$ (magnesium chloride)

- Chamber 2: $63.8 \%$ (magnesium nitrate)

- Chamber 3: $73.4 \%$ (sodium chloride)

- Chamber 4: $82.0 \%$ (potassium chloride)

- Chamber 5: $96.4 \%$ (potassium sulphate)

RH was measured within each chamber using a Tinytag $^{\circledR}$ (Gemini Data Loggers Ltd., UK).

Each of the small experimental units housed within the RH chambers was $12 \times 5 \mathrm{~cm}$ in diameter and had a gauze insert in the lid to stop beetle egress and provide air exchange. The gauze had a thread size of $0.1 \mathrm{~mm}$ and a hole diameter of $0.15-0.30 \mathrm{~mm}$. A sugar cube was provided in each unit for food.

DE treatment $(+)$ was applied by dousing batches of beetles (i.e. 200) en masse with $2.5 \mathrm{~mL}$ of $\mathrm{DE}$ in a glass bowl (diameter, $20 \times 9 \mathrm{~cm}$ ) and agitating for 3-5 s until the beetles were thoroughly covered. Beetles were then gently sieved using a 1-mm aperture sieve to remove excess DE. For treatment without DE $(-)$, beetles were not coated.

Bioassay 3 also tested the hypothesis that the application of DE to SHB significantly increases mortality, but is dependent on relative humidity.

This assay was carried out exactly as for bioassay 2 , except that sugar cubes were omitted. The reason the food was excluded was because in bioassay 2 the sugar, being hygroscopic, liquefied in chambers with
82 and $96 \%$ RH. Since the beetles might have used this fluid to help remove DE from their bodies, or otherwise assist survival, another bioassay was planned in which sugar was excluded.

Bioassay 4 tested the hypothesis that a particulate with the same size and distribution as DE, but not likely to scarify, when applied to the outside of the beetle body, causes significant mortality.

This assay was carried out exactly as for bioassay 3 , except that corn flour was used in place of DE. Corn flour-treated SHB had been examined via SEM (see Section 2.4 above), and the particles were found to have a similar dispersal pattern to $\mathrm{DE}$, clustering under and around the sensilla. Corn flour is absorbent, non-toxic and non-abrasive but rounded and so provides a useful comparison with DE which is considered to be absorptive but possibly scarifying.

\subsection{Humidity and weight change in diatomaceous earth}

The hypothesis tested was that DE changes weight with exposure to a change in RH. The reason for this experiment was that water uptake by DE might have an impact on the efficacy of DE against beetles at different RHs. Understanding water uptake might help explain the results in bioassays 2 and 3 .

There were five replicates (+DE) held at the same five different RHs used in bioassays 2-4. Prior to the experiment, DE was stored at an ambient $\mathrm{RH}$ of $72 \%$. On the first day of the experiment, DE was distributed into plastic pots (each $3.8 \times 4.4 \mathrm{~cm}$ in diameter) of known weight, without lids. The filled pots were weighed again so that the weight of $\mathrm{DE}$ in the pots could be calculated. The sets of five pots were then placed into the humidity chambers. After $24 \mathrm{~h}$, the pots were removed and weighed again. One control pot of known weight was also placed in each $\mathrm{RH}$ chamber and weighed at the end of the experiment to test for weight change in case the pot plastic absorbed water. A Mettler Toledo balance was used for all weighing (accurate to $0.0001 \mathrm{~g}$, model XS3DU, Columbus, OH, USA).

\subsection{Data analysis}

For survival analysis, Cox and the Cox mixedeffects model were used (Ripatti and Palmgren 2000; 
Therneau et al. 2003) and applied via the package 'coxme' (Therneau 2011) with $\mathrm{R}$ for statistical computing (R Development Core Team 2012). Relative humidity and treatment were treated as fixed effects and run and replicate as random effects. Proportional hazards test of assumption (Grambsch and Therneau 1994) was applied to ensure that the data met the assumptions.

Event probability was used to assess the probability of beetle death in bioassay 1 . The Mann-Whitney test was used to assess differences between pairs for bioassays 2, 3 and 4 . Where appropriate, normality was tested with the Anderson-Darling test. Weight change of DE across RH was assessed using ANOVA and Fisher's pairwise comparisons using Minitab for the performed analyses.

\section{RESULTS}

\subsection{Bioassay 1: behaviour and survival of beetles in relation to traps used in-hive}

Figure $2 \mathrm{a}, \mathrm{b}$ shows two beetle trench traps and small hive beetles after exposure to DE in the beetle trench traps, respectively. Beetles had the opportunity to remain in the trench trap or to crawl or fly out of the trap, but remain within the experimental chamber. At the end of 7 days, all the beetles in the DE-filled trench trap treatment were found in the traps and all were assessed as dead. The result was identical in the nine replicates: a mean of $40 \pm 0$ dead, $n=9$. Therefore, the event probability for complete death in DE trench trap replicates $=1$ (certainty). In contrast, for the trial without $\mathrm{DE}$ in trench traps (the control), only $2.5 \%$ of the beetles were found dead in the empty trap, whereas $6.1 \%$ were found outside the trap. Out of a possible 40 beetles, the mean number of dead beetles was only $3.44 \pm 1.14, n=9$ (median=3, mode $=0)$. No control replicates produced total beetle death: event probability $=0$. In summary, average mortality was $8.6 \%$ in the control compared with $100 \%$ mortality in the treatment group.

In all control replicates, larvae were found on the pollen patties. In contrast, no larvae were observed in the treatment replicates and no beetles were observed outside the traps. Beetles were observed coming and going from the traps in the control replicates.

\subsection{Examination of beetle cuticle with scanning electron microscopy}

No scarification of adult beetle cuticle was observed after exposure to DE (Figure 2c). DE particles were found clustered onto the sensilla and in particular were seen to heavily coat the antennal sensilla (Figure 2d, e). Corn flour was similarly distributed to DE, but less dense (Figure 2f).

\subsection{Bioassays 2,3 and 4: effect of relative humidity and particulates on beetle survival}

In bioassay 2, beetle survival was poorest at low RH and with the addition of DE treatment (Figure 3). Analysis is provided in Table I: for the comparison of $\mathrm{RH}=73,82$ and $96 \%$ against $\mathrm{RH}=56 \%$, the difference was significant, as was the case for DE treatment against the control and for the interaction RH96/TreatmentDE. In the tables, it should be noted that the column listing the exponential coefficient $(\operatorname{Exp}(\mathrm{coef}))$ explains the hazard in the treatment group; values $<1$ indicate protective performance and signal increased survival.

With respect to the data meeting the assumptions for the test applied, a global test of proportional hazard assumption was significant $(P=0.04)$, which indicated a slight departure from the assumption for the test applied. However, the rho correlations were all small $(\leq 0.1)$ and the plots of the beta coefficients versus time were all flat, indicating that this was only a minor departure from the assumption and should not seriously affect the interpretation of the analysis.

When the data were split, to assess the effect of humidity separately from DE, both $\mathrm{RH}$ and DE showed a linear trend, with increasing $\mathrm{RH}$ being protective $(P<0.0001$; see Table II).

In bioassay 3 , it was shown that the omission of sugar (food) increased the negative effects of both DE and low humidity on SHB survival 


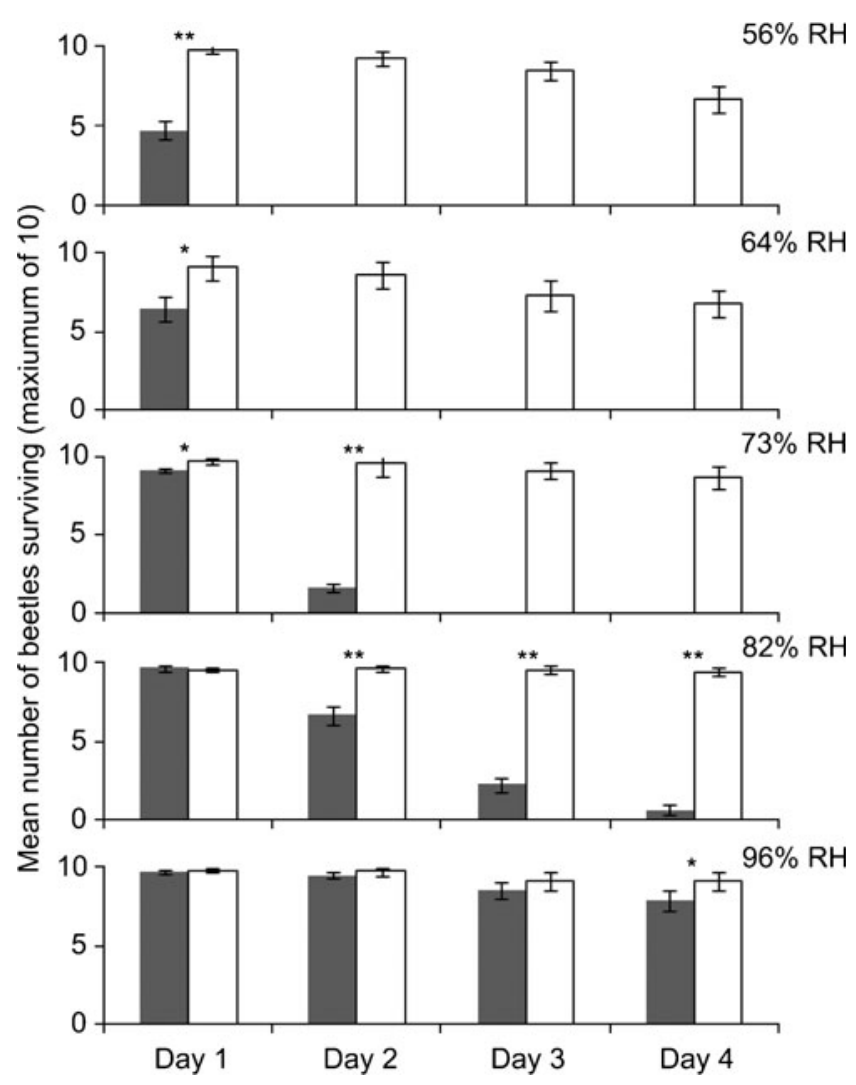

Figure 3. Survival of small hive beetles, $A$. tumida (mean \pm SEM, $n=3$ replicates with four experimental units each) across 4 days at 56, 64, 73, 82 and $96 \%$ relative humidity. Beetles were provided with sugar. A single asterisk indicates a difference of $P \leq 0.05$ between control (white bar) and treatment with diatomaceous earth (dark bar) pair. Two asterisks indicate $P \leq 0.001$ (Mann-Whitney test).

(Figure 4). The results followed the same trends as found for bioassay 2. Table III shows that all $\mathrm{RH}$ comparisons against $\mathrm{RH}=56 \%$ were significant, as was the DE treatment against control and the interactions RH73/TreatmentDE, RH82/TreatmentDE and RH96/TreatmentDE. With respect to data meeting the assumptions for the test applied, a global test of proportional hazard assumption was found to be not significant $(P=0.38)$, demonstrating no departure from the assumption. Both $\mathrm{RH}$ and DE showed a linear trend, with increasing $\mathrm{RH}$ being protective $(P<0.0001$; see Table IV).

At high RH (82 and $96 \%$ ), the absence of sugar appeared to reduce SHB survival and mitigate the protective influence of high $\mathrm{RH}$ on the effect of DE (contrast Figures 3 and 4). Comparing survival for these $\mathrm{RH}$ levels, for bioassays 2 and 3, using the Cox mixed-effects model showed significant differences for treatments $(\mathrm{RH}=82 \%$ : $z=-3.49, P=0.0005$; $\mathrm{RH}=$ $96 \%: z=-2.8, P=0.005)$, whereas a comparison of survival for untreated beetles at these two RH levels, between bioassays 2 and 3, showed no significant difference $(\mathrm{RH}=82 \%: z=-1.39, P=$ 0.16 ; $\mathrm{RH}=96 \%: z=-1.29, P=0.20)$. However, at low RH (56\%), the addition of sugar resulted in better survival of untreated beetles (compare Figures 3 and 4; RH=56 \%: $z=-5.93, P<$ $0.0001)$. Global tests of proportional hazard assumption were not significant $(P=0.41, P=$ $0.41, P=0.60, P=0.10$ and $P=0.11$, respective- 
Table I. Survival analysis with Cox mixed-effects model fit by maximum likelihood assessing exposure to dousing with $\mathrm{DE}$ on the small hive beetle, $A$. tumida, across five different RH environments (56, $64,73,82$ and $96 \%$ ) for four consecutive days: output for fixed coefficients.

\begin{tabular}{|c|c|c|c|}
\hline Comparisons & $\operatorname{Exp}(\operatorname{coef})$ & $z$ & $P$ \\
\hline $\mathrm{RH} 4^{\mathrm{a}}$ & 1.4261 & 0.98 & 0.3300 \\
\hline RH73 & 0.2390 & -3.28 & 0.0010 \\
\hline RH82 & 0.1177 & -4.18 & 0.0003 \\
\hline RH96 & 0.1735 & -3.76 & 0.0002 \\
\hline TreatmentDE $^{\mathrm{b}}$ & 56.6228 & 11.24 & $<0.0001$ \\
\hline RH64/TreatmentDE & 0.5056 & -1.41 & 0.1600 \\
\hline RH73/TreatmentDE & 1.5841 & 0.85 & 0.3900 \\
\hline RH82/TreatmentDE & 0.9842 & -0.03 & 0.9800 \\
\hline RH96/TreatmentDE & 0.0490 & -4.99 & $<0.0001$ \\
\hline
\end{tabular}

${ }^{\text {a }}$ RH64=RH64\% against $56 \%$

${ }^{\mathrm{b}}$ TreatmentDE $=\mathrm{DE}$ against control

ly, for the tests listed), demonstrating that there was no departure from the assumption for the tests applied.

Bioassay 4 assessed the difference in the survival of beetles doused with corn flour compared with untreated beetles (the control). There were no differences between treatment and control for any RH or day (see Figure 5), so it can be concluded that corn flour particulates have no negative effect on the survival and that the effect of DE is specific.

Table II. Demonstration of a linear trend for RH treatments $(56,64,73,82$ and $96 \%)$ on the small hive beetle, $A$. tumida, across four consecutive days when beetles were provided with sugar.

\begin{tabular}{lccl}
\hline RH.Linear & $\operatorname{Exp}(\mathrm{coef})^{\mathrm{a}}$ & $z$ & $P$ \\
\hline Control (no DE) & 0.1090 & -4.66 & $<0.0001$ \\
DE & 0.0320 & -19.040 & $<0.0001$ \\
\hline
\end{tabular}

$D E$ diatomaceous earth

${ }^{\text {a Values }}<1$ indicate protective performance; in this case, signalling increased survival with increasing $\mathrm{RH}$

\subsection{Humidity and weight change in diatomaceous earth}

Weight gain or loss in control pots per treatment - a result of the plastic taking up or losing moisture-was applied to the treatment pots as a correction. A significant difference in weight change for $\mathrm{DE}$ was found across $\mathrm{RH}$ (ANOVA: $\mathrm{F} 4=3.81, P=0.019$ ). Data are presented in Figure 6. Weight was lost at low RH $(\leq 64 \%)$ and gained at a higher RH $(\geq 73 \%)$. The data show that the DE product used can gain and lose moisture from the air, and this will have implications for its use in the field.

\section{DISCUSSION}

Human et al. (2006) and Ellis et al. (2008) noted that a European honeybee colony can only adjust humidity within suboptimal limits and that variation will be in relation to hive and environmental factors. Therefore, hives are influenced by the relative humidity in the air they must use to ventilate their colony. Bees cannot keep their hive at a fixed relative humidity $(\mathrm{RH})$, although they do adjust it with fanning behaviour. Bee fanning is low below $55 \% \mathrm{RH}$ and increases with $\mathrm{RH}$, and this behaviour is aimed at removing humid air (Ellis et al. 2008). Therefore, it can be concluded that hive $\mathrm{RH}$ is unlikely to be maintained at the very high levels where DE is ineffective, although field trials are necessary for confirmation.

We looked at two factors: the effect of relative humidity alone and the effect of $\mathrm{DE}$ at different RH settings. Taking the issue of $\mathrm{RH}$ on its own, we found that the data demonstrate that the survival of adult SHB is affected by atmospheric relative humidity. Specifically, beetle survival is poorest at low $\mathrm{RH}$ and after prolonged exposure. Survival is further impacted by lack of food (sugar), suggesting that beetles may survive poorly in dry weather outside the hive, without food.

The effect of $\mathrm{RH}$ on beetle mortality was significantly enhanced by the application of Absorbicide $^{\circledR}$ diatomaceous earth (DE). Since the efficacy of DE against beetles is greater at 


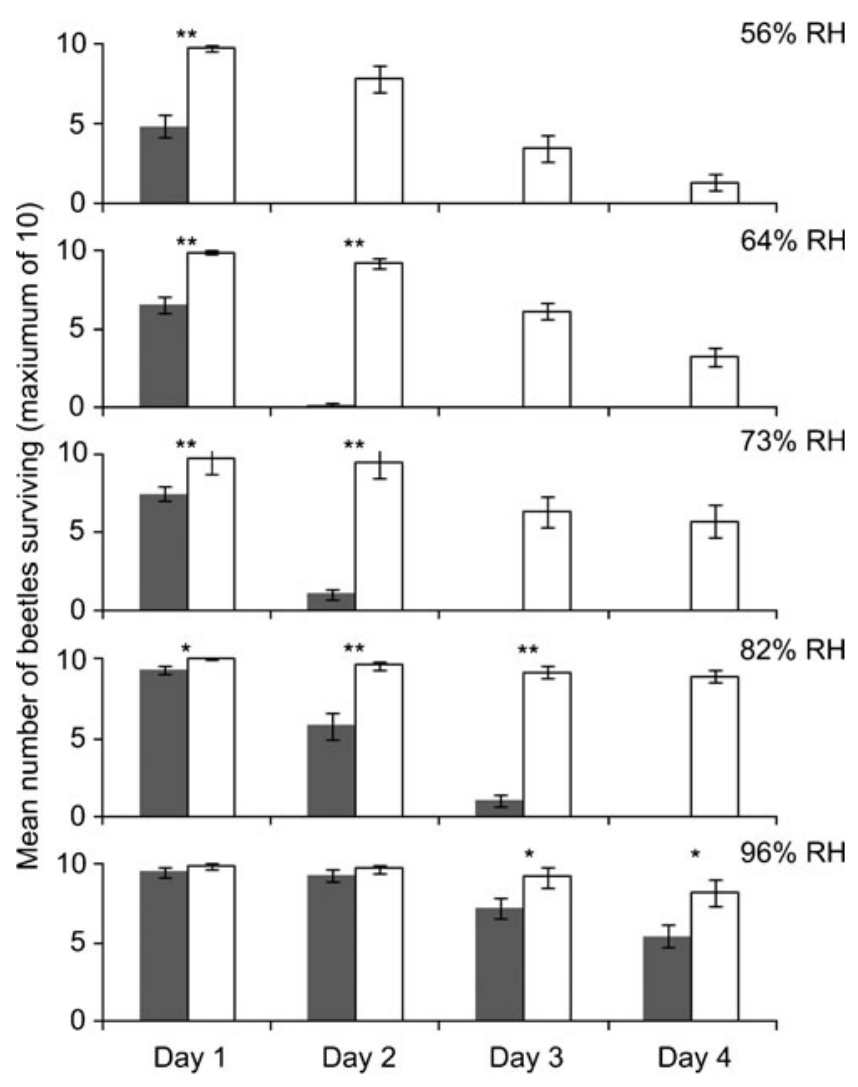

Figure 4. Survival of small hive beetles, $A$. tumida (mean \pm SEM, $n=3$ replicates with four experimental units each) across 4 days at 56, 64, 73, 82 and $96 \%$ relative humidity in the absence of sugar. A single asterisk indicates a difference of $P \leq 0.05$ between control (white bar) and treatment with diatomaceous earth (dark bar) pair. Two asterisks indicate $P \leq 0.001$ (Mann-Whitney test).

low humidity, it is a management tool likely to be most effective for apiarists to use during dry weather spells and in areas where the ambient $\mathrm{RH}$ is low.

Buchholz et al. (2009) studied the application of a different type of DE (Fossil Shield ${ }^{\circledR}$ 90) to adult SHB in the laboratory and field experiments, but not in relation to $\mathrm{RH}$. The bottom board was used to introduce this DE variety into hives in grill-covered trays; $>50 \%$ of the beetles in naturally infested hives perished in 2 days. But concern was raised about endangering bees and their products via DE dust circulating through the hive driven by thermoregulation (bee fanning behaviour). Since the current study finds that the use of DE in the beetle trap is effective at inducing mortality
(>99\%), it provides a suitable method to both contain and introduce DE to the hive, although other, better methods of delivery may be found. Currently, the trap is placed between frames at the top of the hive rather than the bottom where air is drawn in for ventilation; DE is contained within the covered trench, and the trap contains DE in such a way that honeybees will not come in contact with it because the lid slots are too small to allow bee ingress, but of a size that allows beetles to pass through. However, bees should be tested for DE contamination in field trials.

No evidence was found for scarification of adult small hive beetle cuticle after the application of DE. Richards et al. (2005) studied treatment of the small hive beetle with DE (unspecified source) in the presence of fungal 
Table III. Survival analysis with Cox mixed-effects model fit by maximum likelihood assessing exposure to dousing with $\mathrm{DE}$ on the small hive beetle, $A$. tumida, across five different RH environments (56, $64,73,82$ and $96 \%$ ) for four consecutive days: output for fixed coefficients.

\begin{tabular}{lrrr}
\hline Comparisons & Exp(coef) & \multicolumn{2}{l}{$z$} \\
\hline RH64 $^{\mathrm{a}}$ & 0.4833 & -3.45 & 0.0006 \\
RH73 & 0.2437 & -6.23 & $<0.0001$ \\
RH82 & 0.0536 & -9.06 & $<0.0001$ \\
RH96 & 0.0987 & -8.49 & $<0.0001$ \\
TreatmentDE $^{\mathrm{b}}$ & 12.0439 & 11.65 & $<0.0001$ \\
RH64/TreatmentDE $^{2}$ & 1.4617 & 1.32 & 0.1900 \\
RH73/TreatmentDE & 2.0685 & 2.42 & 0.0160 \\
RH82/TreatmentDE & 3.1710 & 3.03 & 0.0025 \\
RH96/TreatmentDE & 0.2376 & -4.04 & $<0.0001$ \\
\hline
\end{tabular}

${ }^{a}$ RH64=RH64\% against $56 \%$

${ }^{\mathrm{b}}$ TreatmentDE $=\mathrm{DE}$ against control

spores to assess whether this combination increased mortality. Whilst it did not assist in pupal mortality, lacerations were observed between segments of larvae treated with DE. Larvae, however, are likely to have softer cuticles than adults, and this may explain the absence of scarification or lacerations in our study where adults were used. Alternatively, the diatoms making up the DE may differ in morphology from those used in the study by Richards et al. (2005). However, the lack of scarification in the current study in addition to the high mortality suggests that scarification is

Table IV. Demonstration of a linear trend for RH treatments $(56,64,73,82$ and $96 \%)$ on the small hive beetle, A. tumida, across four consecutive days when beetles were not provided with sugar.

\begin{tabular}{llll}
\hline RH.Linear & $\operatorname{Exp}(\mathrm{coef})$ & $\mathrm{a}$ & \multicolumn{1}{l}{$P$} \\
\hline Control (no DE) & 0.1064 & -8.76 & $<0.0001$ \\
DE & 0.06179 & 18.52 & $<0.0001$ \\
\hline
\end{tabular}

$D E$ diatomaceous earth

${ }^{\text {a Values }}<1$ indicate protective performance, in this case signalling increased survival with increasing $\mathrm{RH}$. not necessary for the efficacy of DE as a management tool for SHB. Although comparison with corn flour shows that it is not merely the presence of a particulate that results in greater mortality, the effect is specific to DE.

$\mathrm{DE}$ is thought to increase water loss from insects, thereby desiccating them (Mewis and Ulrichs 2001; Ulrichs et al. 2006), and this effect is likely enhanced by DE adsorption of lipids from insect cuticle, rendering the cuticle more permeable to water and, therefore, its loss (Ebeling 1961). It has been reported that DE adsorbs moisture from the air at low $\mathrm{RH}$ (Michalaki et al. 2006). The current study found that DE lost weight at low $\mathrm{RH}$, indicating that residual water was evaporating into the air. At the same low RH, SHB mortality increased with DE treatment. Mewis and Ulrichs (1999) noted that the lipid-binding capacity of DE from different sources may vary. It is logical to reason that DE would function better at low ambient RH because it is drier and therefore has an enhanced capacity to adsorb fluids when in direct contact with them, such as via the surface of the SHB. Here, wicking of liquid waxes may be possible through the micro-canal system of the cuticle, affecting water loss in the process.

Our study demonstrated that DE was effective in causing mortality at low RH, but the effect of DE was reduced at high RH. The effect was linear. In contrast, the weight increase of DE exposed to increasing $\mathrm{RH}$ did not yield a linear relationship (Figure 6), which is surprising. Further research is needed to explore why this might be the case. Putting aside the lack of linearity, there is still the established trend that DE absorbs more water from the air at high RH. Such uptake presumably decreases the capacity of DE to adsorb fluids from beetles and may explain the higher survival rates at high $\mathrm{RH}$. But even if DE were still able to be effective in the adsorption of fluids at high $\mathrm{RH}$, another as yet unconsidered factor might be more important in determining insect survival. That factor is the naturally lower water loss that would occur at higher RH. Cuticle rendered unable to physiologically control water retention, but surrounded by an environment with high $\mathrm{RH}$ would be 


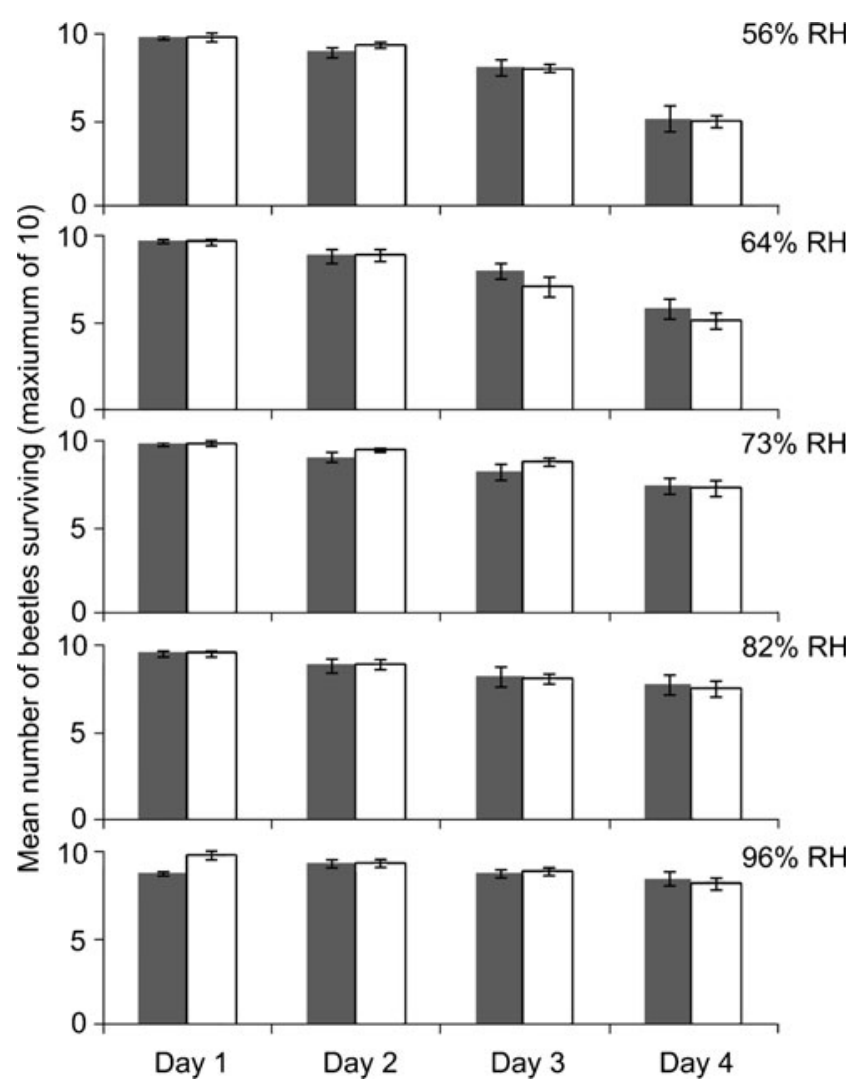

Figure 5. Survival of small hive beetles, $A$. tumida (mean \pm SEM, $n=3$ replicates with four experimental units each) across 4 days at 56, 64, 73, 82 and $96 \%$ relative humidity. Beetles were provided with sugar. There are no significant differences between control (white bar) and treatment with corn flour (dark bar) pairs (MannWhitney test).

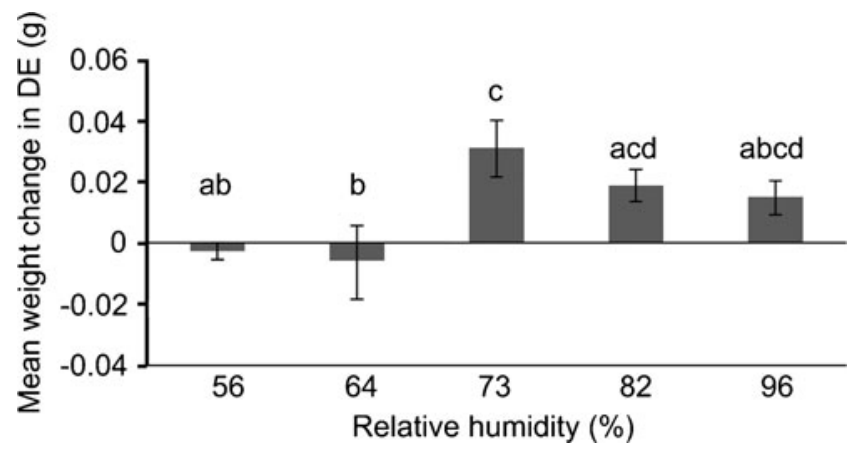

Figure 6. Weight change of diatomaceous earth (mean $\pm \mathrm{SEM}, n=5$ replicates) after exposure to one of five relative humidity environments $(56,64,73,82$ and $96 \%$ ) for $24 \mathrm{~h}$. Bars with a different letter are significantly different $(P \leq 0.05$; Fisher's pairwise comparisons following ANOVA). 
protected. It is known that insects can moderate their water loss in such situations under moist conditions (Mewis and Ulrichs 2001). So even if $\mathrm{DE}$ were effective at removing lipids from insect cuticle at high $\mathrm{RH}$, the insects would probably not lose water at the rate needed for significant mortality.

The use of corn flour as a comparative particulate for DE raises some questions. Since it is a source of carbohydrate, there is the possibility that beetles might obtain it from their surfaces and consume in and that this might affect the experimental outcome. There is no evidence that it was consumed. Very little has been published about corn flour as a source of nutrition for arthropods. Guo et al. (2006) included it into food stock for the white shrimp, Litopenaeus vannamei, indicating that these authors considered it nutritious. Gómez et al. (2012) used it as "a nutrient-poor artificial diet" for Daphnia, another crustacean. No data are available for arthropods similar to the small hive beetle that feed on honey and bee brood.

But if corn flour from the beetle surface was consumed, and was utilised as food, would this have compromised the result and conclusion? Yes, it would, if it somehow masked mortality. But do we see this in bioassay 2 where sugar was supplied and is known to be a food that is consumed? When the outcomes from bioassay 2 (where sugar was present) and bioassay 3 (where sugar was absent) are compared, there is a small positive effect associated with the presence of sugar, but it is not enough to mask the significant mortality associated with DE. We would therefore not expect consumption of corn flour to mask similar significant mortality produced by external application of corn flour particulates. Since there was no significant difference between corn flour treatment and control in the bioassay 4 data, we can be confident that the applied corn flour particulates do not induce mortality.

Other factors related to the way in which DE affects the survival of the SHB have yet to be investigated. For example, does the presence of $\mathrm{DE}$ on a beetle, even in conditions that do not cause mortality, affect its locomotion, interaction and/or reproduction? The current study shows that coated beetles in trench traps do not escape and therefore cannot reproduce. However, other methods of application may result in a lesser coating, and it would therefore be useful to investigate mobility and chemosensory orientation in poorly coated individuals. We noted a significant adhesion of DE to the antennae and their sensilla, which may impact chemosensory orientation. However, of more immediate importance is field testing of DE in SHB traps within hives.

\section{ACKNOWLEDGMENTS}

We thank Gary Everingham and Kate McGlashan for beetle rearing and laboratory assistance, and Woncheol (Delphino) Jung, who undertook a trial investigation into this topic as a student project under our guidance. The Rural Industries Research and Development Corporation honeybee program provided funding to support some of this work. The authors have no commercial interest in the marketing of the trap used in the study.

Essai de lutte contre le petit coléoptère des ruches, Aethina tumida, par utilisation de l'humidité relative et de terre de diatomées

Absorbicide ${ }^{\circledR} /$ Apis mellifera / abeille européenne / piège à coléoptère / ennemi de la ruche

Schädlingsmanagement des Kleinen Beutenkäfers (Aethina tumida) durch Einsatz von relativer Feuchte und Diatomeenerde

Absorbicide $®$ / Apis mellifera / Europäische Honigbiene / Insekten / Käferfalle

\section{REFERENCES}

Annand, N. (2011) Small hive beetle biology_-Producing control options. Rural Industries Research and Development Corporation Publication No. 11/044. Print-on-demand by Union Offset Printing, Canberra

Benda, N.D., Boucias, D., Torto, B., Teal, P. (2008) Detection and characterization of Kodamaea ohmeri associated with small hive beetle Aethina tumida infesting honey bee hives. J. Apic. Res. 47, 194-201

Bennett, D.C., Yee, A., Rhee, Y.J., Cheng, K.M. (2011) Effect of diatomaceous earth on parasite load, egg 
production, and egg quality of free-range organic laying hens. Poultry Sci. 90, 1416-1426

Buchholz, S., Merkel, K., Spiewok, S., Pettis, J.S., Duncan, M., Spooner-Hart, R., Ulrichs, C., Ritter, W., Neumann, P. (2009) Alternative control of Aethina tumida Murray (Coleoptera: Nitidulidae) with lime and diatomaceous earth. Apidologie 40, 535-548

Ebeling, W. (1961) Physiochemical mechanism for the removal of insect wax by means of finely divided powders. Hilgardia 30, 531-564

Ellis, M.B., Nicolson, S.W., Crewe, R.M., Dietemann, V. (2008) Hygropreference and brood care in the honeybee (Apis mellifera). J. Insect Physiol. 54, 1516-1521

Faulde, M.K., Tisch, M., Scharninghausen, J.J. (2006) Efficacy of modified diatomaceous earth on different cockroach species (Orthoptera, Blattellidae) and silverfish (Thysanura, Lepismatidae) J. Pest Sci. 79, 155-161

Fields, P., Korunic, Z. (2000) The effect of grain moisture content and temperature on the efficacy of diatomaceous earths from different geographical locations against stored-product beetles. J. Stored Prod. Res. 36, 1-13

Golob, P. (1997) Current status and future perspectives for inert dusts for control of stored product insects. J. Stored Prod. Res. 33, 69-79

Gómez, M., Martìnez, I., Mayo, I., Morales, J.M., Santana, A., Packard, T.T. (2012) Testing zooplankton secondary production models against Daphnia magna growth. ICES J. Mar. Sci. 69, 421-428

Grambsch, P., Therneau, T. (1994) Proportional hazards tests and diagnostics based on weighted residuals. Biometrika 81, 515-526

Guo, R., Liu, Y.-J., Tian, L.-X., Huang, J.-W. (2006) Effect of dietary cornstarch levels on growth performance, digestibility and microscopic structure in the white shrimp, Litopenaeus vannamei reared in brackish water. Aquac. Nutr. 12, 83-88

Human, H., Nicolson, S.W., Vincent, D. (2006) Do honeybees, Apis mellifera scutellata, regulate humidity in their nest? Naturwissenschaften 93, 397-401

Korunic, Z. (1998) Diatomaceous earths, a group of natural insecticides. J. Stored Prod. Res. 34, 87-97

Lounsberry, Z., Spiewok, S., Pernal, S.F., Sonstegard, T.S., Hood, W.M., Pettis, J., Neumann, P., Evans, J.D. (2010) Worldwide Diaspora of Aethina tumida (Coleoptera: Nitidulidae), a nest parasite of honey bees. Ann. Entomol. Soc. Am. 103, 671-677

Mewis, I., Ulrichs, C. (1999) Wirkungsweise amorpher Diatomeenerden auf vorratsschädliche Insekten. Untersuchung der abrasiven sowie sorptiven Effekte. Anz. Schädlingskd. 72, 113-121

Mewis, I., Ulrichs, C. (2001) Action of amorphous diatomaceous earth against different stages of the stored product pests Tribolium confusum (Coleoptera: Tenebrionidae), Tenebrio molitor (Coleoptera: Tenebrionidae), Sitophilus granarius (Coleoptera: Curculionidae) and Plodia interpunctella (Lepidoptera: Pyralidae). J. Stored Prod. Res. 37, 153-164
Michalakia, M.P., Athanassioua, C.G., Kavallieratosb, N.G., Battac, Y.A., Balotisd, G.N. (2006) Effectiveness of Metarhizium anisopliae (Metschinkoff) Sorokin applied alone or in combination with diatomaceous earth against Tribolium confusum Du Val larvae: Influence of temperature, relative humidity and type of commodity. Crop. Prot. 25, 418-425

Mucha-Pelzer, T., Debnath, N., Goswami, A., Mewis, I., Ulrichs, C. (2008) Bekämpfung von Epilachna vigintioctopunctata und Spodoptera litura F. mit Silikaten. Gesunde Pflanz 60, 23-28

Neumann, P., Hoffmann, D., Duncan, M., Spooner-Hart, R. (2010) High and rapid infestation of isolated commercial honey bee colonies with small hive beetles in Australia. J. Apic. Res. 49, 343-344

R Development Core Team (2012) R: A language and environment for statistical computing. R Foundation for Statistical Computing, Vienna, Austria. ISBN 3900051-07-0. http:/www.R-project.org/

Richards, C.S., Hill, M.P., Dames, J.F. (2005) The susceptibility of small hive beetle (Aethina tumida Murray) pupae to Aspergillus niger (van Tieghem) and A. flavus (Link: Grey). Am. Bee J 145, 748-751

Ripatti, S., Palmgren, J. (2000) Estimation of multivariate frailty models using penalized partial likelihood. Biometrics 56, 1016-1022

Stadler, T., Buteler, M., Weaver, D.K., Sofie, S. (2012) Comparative toxicity of nanostructured alumina and a commercial inert dust for Sitophilus oryzae (L.) and Rhyzopertha dominica (F.) at varying ambient humidity levels. J. Stored Prod. Res 48, 81-90

Therneau, T. (2011) coxme: Mixed effects Cox models. R package version 2.2-1. http://CRAN.R-project.org/ package $=$ coxme

Therneau, T., Grambsch, P., Pankratz, V.S. (2003) Penalized survival models and frailty. J. Comput. Graph. Stat. 12, 156-175

Thompson, S.R., Brandenburg, R.L. (2006) Effect of combining imidacloprid and diatomaceous earth with Beauveria bassiana on mole cricket (Orthoptera: Gryllotalpidae) mortality. J. Econ. Entomol. 99, 1948-1954

Torto, B., Fombong, A.T., Arbogast, R.T., Teal, P.E.A. (2010) Monitoring Aethina tumida (Coleoptera: Nitidulidae) with baited bottom board traps: Occurrence and seasonal abundance in honey bee colonies in Kenya. Environ. Entomol. 39, 1731-1736

Ulrichs, C., Entenmann, S., Goswami, A., Mewis, I. (2006) Abrasive und hydrophil/lipophile Effekte unterschiedlicher inerter Stäube im Einsatz gegen Schadinsekten am Beispiel des Kornkäfers Sitophilus granarius L. Gesunde Pflanz 58, 173-181

Völk F., Reichmuth Ch., Ulrichs Ch. (2004) Wirksamkeitsüberprüfung hydrophobisierter Diatomeenerden bei unterschiedlichen relativen Lufteuchten gegenüber vorratsschädlichen Insekten. Deutsche Pflanzenschutztagung, Hamburg, 20-23 Sept., Mitteilungen aus der Biologischen Bundesanstalt für Land-und Forstwirtschaft 54, pp. $396-441$ 